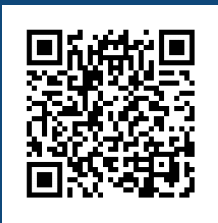

Keywords:

Carbohydrate storage High-throughtput phenotyping Resilience

Starch

Sugar

Historic:

Received 14/| |/2018 Accepted 21/01/2019

+Correspondence: lucasrosado@yahoo.com.br
Lucas Rodrigues Rosado ${ }^{\mathrm{la}+}$, Luiz Mendes Takarada ${ }^{\mathrm{l}}$, Ana Clara Caxito de Araújo ${ }^{\mathrm{lc}}$, Kamila Rezende Dázio de Souza ${ }^{2 a}$, Paulo Ricardo Gherardi Hein ${ }^{\text {ld }}$, Sebastião Carlos da Silva Rosadole, Flávia Maria Avelar Gonçalves ${ }^{\prime f}$

\section{NEAR INFRARED SPECTROSCOPY: RAPID AND ACCURATE ANALYTICAL TOOL FOR PREDICTION OF NON-STRUCTURAL CARBOHYDRATES IN WOOD}

ROSADO, L. R.; TAKARADA, L. M.; ARAÚJO, A. C. C.; SOUZA, K. R. D.; HEIN, P. R. G.; ROSADO, S. C. S.; GONÇALVES, F. M. A. Near infrared spectroscopy: rapid and accurate analytical tool for prediction of non-structural carbohydrates in wood. CERNE, v. 25, n. I, p. 84-92, 2019.

\section{HIGHLIGHTS}

NIR spectroscopy has yielded promissory estimates of the NSC in wood.

NIR signatures taken from wood powders are more informative for NSC modeling.

NSC predictions from wood disc spectra provided satisfactory responses.

Breeders can understand the resilience of trees using NSC estimates by NIR.

\section{ABSTRACT}

The non-structural carbon reserves in the various organs of trees are associated with their growth and the mechanism of resilience when exposed to environmental stresses, especially the water deficit. The goal of this study was to develop multivariate models to estimate the amount of non-structural carbohydrates (starch, sucrose, reducing sugars, total sugars and total non-structural carbohydrates) based on near infrared (NIR) spectra measured in solid wood and material reduced to powder. Partial least squares regression was used to associate the amount of non-structural carbohydrates (NSC) obtained by conventional laboratory analysis with NIR spectral signatures. The best predictive models were obtained from the wood reduced to powder. Validity for the NSC prediction in an external set of data presented the following statistics: reducing sugars with $R^{2}=0.90$ and root mean square error (RMSE) of $2.54 \%$ dry matter, total sugars $\left(R^{2}=0.88, R M S E=2.76 \%\right)$, total NSC $\left(R^{2}=0.90, R M S E=2.58 \%\right)$, sucrose $\left(R^{2}=0.82\right.$, $\mathrm{RMSE}=0.06 \%)$ and starch $\left(\mathrm{R}^{2}=0.80, \mathrm{RMSE}=1.03 \%\right)$. The ability of models to estimate the NSC concentration in the growth rings and under divergent environmental conditions demonstrates the potential of the NIR tool to study the physiological responses of plants to different environmental stresses.
' Federal University of Lavras, Lavras, Minas Gerais, Brazil - ORCID: 0000-0002-0249-7968, 0000-0002-4I30-

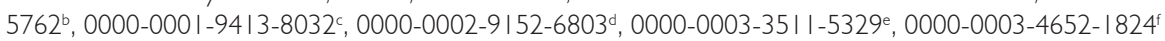
${ }^{2}$ Federal University of Alfenas, Alfenas, Minas Gerais, Brasil - ORCID: 0000-000 I-9264-23822a. 


\section{INTRODUCTION}

Non-structural carbons are organic reserves that act in biochemical processes during the growth, development and survival of plants when subjected to stress situations imposed by the environment. These compounds are simple soluble sugars (glucose, fructose and sucrose), starch, lipids, amino acids, fatty acids and alcohols, being the first two the most significant portion of the energy reserves stored in plants (Hoch et al., 2003; Locosselli and Buckeridge, 2017). Thus, the amount of these reserves available to the plant can be used as important indicators of its potential for growth (Quentin et al., 20II) and its ability to survive environmental stresses (McDowell et al., 20I I; O'Brien et al., 20I4). These facts, associated with the aforementioned relationships between the levels of nonstructural carbohydrates (NSC) reserves and the growth and survival of plants, allow us to conjecture that greater genetic gains for growth and resilience to stress can be achieved by breeding.

For the quantification of NSC, enzymatic extraction techniques and chromatographic procedures are used (Yemm and Willis, 1954; Miller, 1959). However, the laboratory procedures used to detect and quantify NSC are complex, costly and time-consuming, making it difficult to conduct studies that require evaluations in large numbers of samples. To minimize such situations, it is necessary to use techniques that can provide immediate results, but with precision and accuracy close to those provided by traditional methodologies.

In forest sciences, NIR spectroscopy is a nondestructive technique that has been used to estimate wood properties (Tsuchikawa and Kobori, 20I5) because of its precision, speed and effectiveness (Schimleck, 2008), making possible to carry out genetic studies (Estopa et al., 2017). In addition, the technique has the advantage of providing results with high repeatability, requiring minimal sample preparation when compared to traditional analytical methods, and allowing the evaluation of large samples (Viana et al. 2009). The predictions are based on NIR spectral signature, which are related to the composition and the chemical bonds of the analyzed material (Pasquini, 2018).

Few studies have been conducted in forest species tissues to predict non-structural carbohydrates by NIR spectroscopy. Ramirez et al. (20I5) adjusted multivariate models for the quantification of NSC in different organs of 82 native trees from different biomes of Canada and Colombia. The authors evaluated the total free sugars, starch and NSC content. Wang et al. (2018) have studied the growth and production of Picea abies roots with the supply of non-structural carbohydrates present in the different organs of the trees by means of the NIR spectroscopy. However, the fit of multivariate models to quantify NSC was not explored.

In this context, the present study aimed to develop models to estimate the contents of starch, sucrose, reducing sugars, total sugars and total NSC based on NIR spectral signature recorded from samples of solid wood disc and reduced to powder.

\section{MATERIAL AND METHODS}

\section{Biological material}

Samples of Toona ciliata M. Roemer var. australis with seven years old of age were collected from the

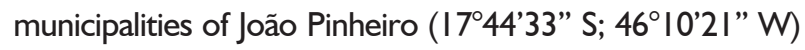

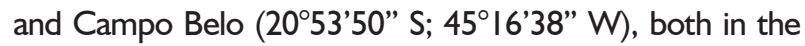
State of Minas Gerais, Brazil. According to Köppen (1948), the climate of the region of João Pinheiro (JP) is classified as Aw: tropical climate with dry winter. Campo Belo (CB) is classified as $C$ wa: subtropical, rainy and mesothermal.

Four clones (FE, XB, XD and XE) represented by three individuals were used, being 12 trees per municipality, totalizing 24 sampled trees.

\section{Wood specimens}

$40 \mathrm{~mm}$ thick discs were taken from each tree at a height of I . 30 meters from the ground. These samples were stored in Styrofoam boxes with ice to reduce the enzymatic activity and the possible oxidation of the material.

In the laboratory, the discs were subjected to the microwave for 90 seconds at $600 \mathrm{~W}$ to denature the enzymes, as described by Popp et al. (1996). Afterwards, they were taken to a forced air circulation oven at $60^{\circ} \mathrm{C}$ to constant mass for complete removal of the water without altering the starch for thermal degradation. The cross-sectional surfaces of the discs were sanded with 60,120 and 180 sandpapers, in order to better reveal and individualize the growth rings.

\section{Spectral Acquisition}

The Bruker FT-NIR spectrometer (Optik GmbH, Ettlingen, Germany), MPA model, with integrating sphere and interferometer, was used to collect the spectra directly on the cross-sectional surface of each disc, positioned at two opposite points of each growth ring, by means of the optical fiber in the range from 12,500 $\mathrm{cm}^{-1}$ to $3,500 \mathrm{~cm}^{-1}$ with a spectral resolution of $8 \mathrm{~cm}^{-1}$ in diffuse reflection mode. Each spectrum represented the average of 16 scans. 
After collecting the spectra in the discs, the growth rings were individualized, reducing them to splinters, with the aid of a planer. The splinters were milled in a 40 mesh sieve for particle size classification and the powder was stored in plastic bags and saved in a freezer at $-20^{\circ} \mathrm{C}$. The powder spectral was acquired through by the integrating sphere with the same features of the disc spectral resolution.

The spectral acquisitions, in the solid wood disc and in powder, were carried out in a heated room $\left(17^{\circ} \mathrm{C}\right.$ and $\left.60-65 \% \mathrm{RH}\right)$ and collected through the software OPUS 7.5.

\section{NSC chemical analysis}

Powder aliquots $(0.200 \mathrm{~g})$ were taken from each sample for the extraction of sugars (reducing sugars and sucrose). Samples were homogenized in $100 \mathrm{mM}$ potassium phosphate buffer, $\mathrm{pH} 7.0$, and then warmed in a water bath at $40^{\circ} \mathrm{C}$ for 30 minutes. The homogenate was centrifuged at $5,000 \mathrm{~g}$ for 10 minutes, and the supernatant was collected. The supernatant was used for sucrose extraction and quantification of reducing sugar. The pellet was resuspended and used for starch extraction (Zanandrea et al., 20I0).

For the determination of sucrose, $800 \mu \mathrm{L}$ micromolecule extract was added to $800 \mu \mathrm{L} 30 \% \mathrm{KOH}$ (Van Handel, 1968), placed in a water bath at $37^{\circ} \mathrm{C}$ for 15 minutes and quantified by the Antrona method (Yemm and Willis, 1954)

Reducing sugars were quantified by the Dinitrosalicylic Acid Method (DNS), according to Miller (1959). The total sugars were represented by the sum of the sucrose with the reducing sugars contents.

To determine the starch, the extraction precipitate was resuspended with $8 \mathrm{~mL}$ of the $200 \mathrm{mM}$ potassium acetate buffer $\mathrm{pH} 4.8,2 \mathrm{~mL}$ of $\mathrm{Img} / \mathrm{mL}$ amyloglucosidase enzyme was added and the sample was incubated in a water bath at $40^{\circ} \mathrm{C}$ for 2 hours. After incubation, the material was centrifuged at $10,000 \mathrm{~g}$ for 20 minutes, the supernatant was collected and the volume of the material was completed to $15 \mathrm{~mL}$ with distilled water. Starch determination was done by the Antrona method (Yemm and Willis, 1954).

The content of total non-structural carbohydrates (total NSC) was determined by summing the total sugars and starch.

The NSC concentrations are expressed as percentage of dry matter (\%DM) according to Equation I.

$N S C(\% D M)=\frac{N S C(\mu \mathrm{m} \text { ol glucose }) \times 180(\text { molecular weight of glucose })}{10^{6}} \cdot 100$
Multivariate analysis

NIR spectra are subjected to interference from several factors, and therefore, the pretreatment of the data collected in the spectrum is necessary to reduce noise and improve calibration fit and validation of the models to be predicted.

Thus, the spectra used for the calibration of the models to predict the NSC contents were filtered, using only the wavenumbers from 9,000 to $4,000 \mathrm{~cm}^{-1}$.

Principal component analyses were performed to detect outliers. After the analysis, outlier detection tests were also carried out, observing leverages $\mathrm{x}$ studentized residuals plots, for each NSC content.

Finally, for the analyses, the spectral data were treated by the first derivative of second-degree polynomials using the Savitzky and Golay (1964) algorithm, with 15 smoothing points, since these led to better results when compared to the original spectra.

The selected samples were analyzed by two methods. The first considered all samples with complete cross validation. In the second approach, the samples were divided into two subsets: calibration (66\%) and external validation (33\%). The selection of samples from each subset was performed using the Kennard-Stone algorithm (Kennard and Stone, 1969).

Partial Least Squares Regression (PLS-R) was applied to associate the variations in the spectra (Matrix $X$ ) with the variations in the NSC (Matrix Y). The selection of the best regression models was based on the following criteria: coefficient of determination $\left(R^{2}\right)$, root mean square error (RMSE) and the ratio of performance to deviation (RPD) (Equation 2), where RPD is the ratio of the standard deviation (SD) of the sample to the root mean square error.

$R P D=\frac{S D}{R M S E}$

All the statistical analyses were run using the software Chemoface version I.5 (Nunes et al., 2012).

\section{RESULTS AND DISCUSSION}

\section{NIR spectra and its pre-treatments}

Figure I illustrates the near infrared signatures taken from wood disc and powder samples.

With the spectra of the different types of sample preparation, principal component analyses were performed, removing one outlier from the disc spectrum and two for the powdered material. In addition, a clone of the environment of João Pinheiro drastically reduced 

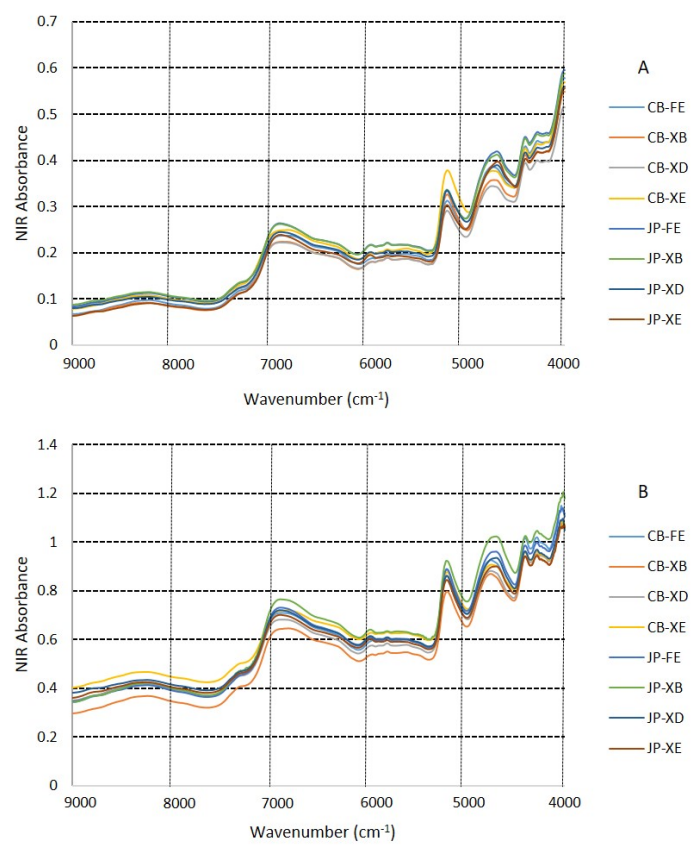

FIGURE I Original NIR spectra collected on powder-reduced material $(A)$ and wood disc $(B)$.

the fit of the model for starch analysis. This may have been due to errors in the execution of laboratory protocols. Thus, the spectra along with their reference values were discarded, justifying the $\mathrm{N}$ of I 47 used for calibration of this characteristic.

Prior to calibration, all spectra were preprocessed by different techniques to eliminate or minimize variability that are not related to the characteristics studied. The best results, which gave the lowest RMSEcv values, were obtained using the Savitzky - Golay first derivative, with different points for each NSC evaluated. The graphs of the treated spectra are shown in Figure 2.

\section{Principal Component Analysis}

The principal component analysis of spectra treated by the first derivative (Figure 3 ) were performed in the two physical forms, disc (I) and powder (2) to distinguish the locations of each material (Figure 3A), the clones present in the study (Figure $3 \mathrm{~B}$ ) and the growth rings (Figure $3 \mathrm{C}$ ) of each tree sampled. In the disc, two distinct groups were formed for the different localities, but with some similarities between them, a factor that is associated with the different clones used, to the powder two distinct groups were formed, but with similar areas, a factor associated with the growth rings sampled, however the distinction of localities is more evident to the powder. No distinction or grouping was observed for the clones, considering the results obtained, except for the $X B$ clone in the powder sampling. For the growth rings, with some similarities due to the divergent sites,
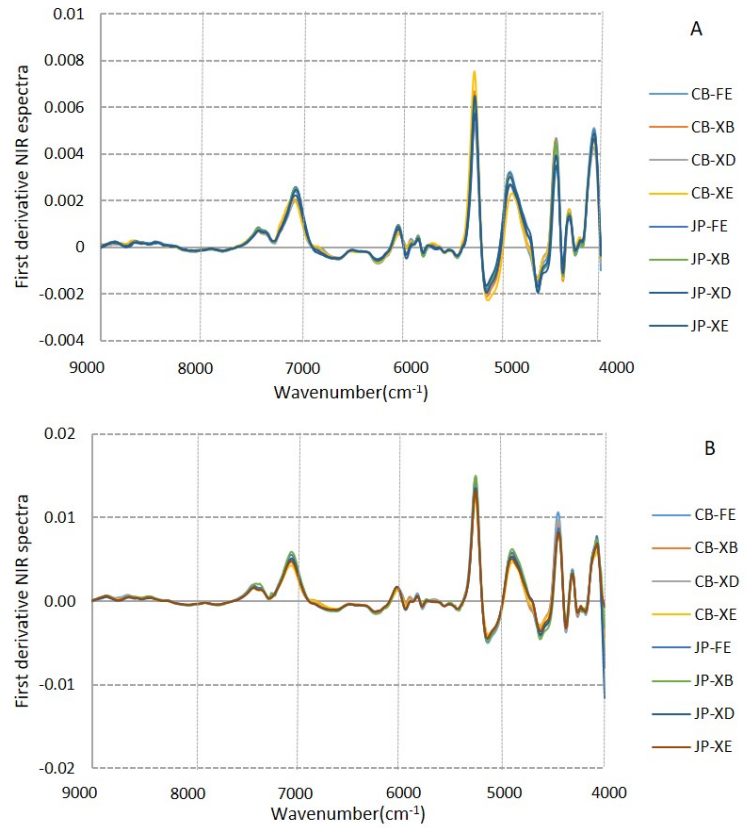

FIGURE 2 Spectra treated by the first derivative of the NIR collected on powder-reduced material $(A)$ and the wood disc (B) $)^{-1}$.

4 distinct groups were formed: group I (rings I, 2, 3 and 4), group 2 (ring 5), group 3 (ring 6) and group 4 (ring 7). This divergence or grouping is deduced by the presence of active cells in the different types of wood (adult or juvenile), specific physiological needs in each ring for the non-structural carbohydrates and the flow of these carbohydrates under different water regimes for the repair of the embolized vessels (Deslauriers et al., 2009; Nardini et al., 20I I). In the powder, the distinction between localities was more evident than that represented by the spectra collected on the disc. For the clones, there was also more evident grouping and similarities, but for the different growth rings, the grouping is more noticeable in the disc material.

\section{Partial Least Squares Regression (PLS-R)}

PLS-R of the spectra obtained by the NIR and the reference values produced satisfactory calibration models for all studied NSC (Table I).

By the descriptive analysis of the mean, maximum, minimum and standard deviation, a high variation between the NSC of samples were observed. This was due to the difference between the two environments studied (Rainfall: Campo Belo - I,406 mm annually and João Pinheiro - I,24I mm), climate changes over time, carbohydrate mobility between rings, which marked the annual growth of the Toona ciliata and four different clones. 

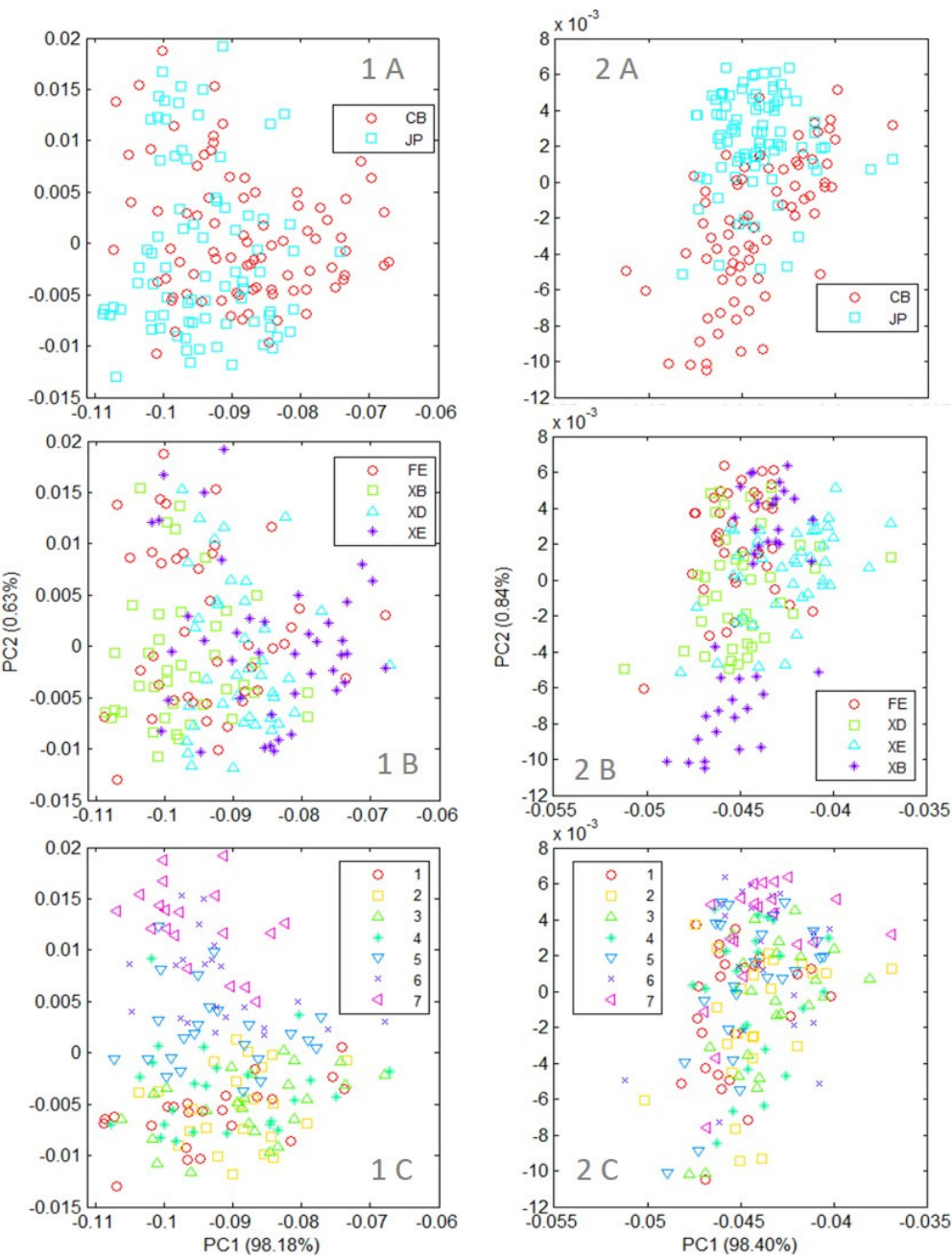

FIGURE 3 PCA scatter plot for the spectra indicating different localities (A), clones (B), growth rings of each sampled tree (C), Disc (I) and Powder (2); Growth rings: I, 2, 3, 4, 5, 6 and 7.

TABLE I Parameters of the PLS-R models according to the type of non-structural carbohydrate in wood discs and powder.

\begin{tabular}{|c|c|c|c|c|c|c|c|c|c|c|}
\hline \multirow{2}{*}{$\begin{array}{c}\text { NSC } \\
\text { Models } \\
\end{array}$} & \multicolumn{2}{|c|}{ Starch } & \multicolumn{2}{|c|}{ Sucrose } & \multicolumn{2}{|c|}{ Reducing sugars } & \multicolumn{2}{|c|}{ Total sugars } & \multicolumn{2}{|c|}{ Total NSC } \\
\hline & Disc & Powder & Disc & Powder & Disc & Powder & Disc & Powder & Disc & Powder \\
\hline \multicolumn{11}{|c|}{ Calibration } \\
\hline Number of samples & 97 & 98 & 110 & 107 & 110 & 108 & 110 & 109 & 109 & 105 \\
\hline Number of outliers & 1 & 8 & 6 & 8 & 3 & 6 & 3 & 4 & 4 & 10 \\
\hline LV & 10 & 10 & 12 & 10 & 7 & 10 & 6 & 10 & 7 & 13 \\
\hline Minimum (\%DM) & 0.19 & 0.19 & 0.02 & 0.03 & 0.25 & 0.03 & 0.29 & 0.06 & 0.49 & 0.49 \\
\hline Maximum (\%DM) & 15.52 & 12.17 & 0.85 & 0.85 & 39.07 & 39.07 & 39.34 & 39.34 & 40.01 & 40.01 \\
\hline Mean (\%DM) & 2.45 & 2.06 & 0.22 & 0.23 & 8.28 & 9.38 & 8.49 & 9.83 & 10.87 & 12.25 \\
\hline SD (\%DM) & 2.89 & 2.07 & 0.19 & 0.17 & 7.50 & 8.37 & 7.56 & 8.66 & 7.45 & 8.45 \\
\hline $\mathrm{R}^{2} \mathrm{c}$ & 0.83 & 0.92 & 0.93 & 0.92 & 0.80 & 0.95 & 0.79 & 0.95 & 0.79 & 0.97 \\
\hline RMSEc (\%DM) & 1.18 & 0.57 & 0.05 & 0.05 & 3.38 & 1.85 & 3.41 & 1.91 & 3.41 & 1.50 \\
\hline \multicolumn{11}{|l|}{ Validation method } \\
\hline $\mathrm{R}^{2} \mathrm{CV}$ & 0.67 & 0.69 & 0.84 & 0.83 & 0.73 & 0.89 & 0.73 & 0.90 & 0.69 & 0.89 \\
\hline RMSEcv (\%DM) & 1.66 & 1.16 & 0.07 & 0.07 & 3.86 & 2.72 & 3.90 & 2.78 & 4.18 & 2.77 \\
\hline RPDev & 1.75 & 1.79 & 2.70 & 2.24 & 2.01 & 3.08 & 1.94 & 3.11 & 1.79 & 3.04 \\
\hline \multicolumn{11}{|c|}{ External Validation } \\
\hline Number of samples & 49 & 46 & 54 & 53 & 55 & 54 & 55 & 55 & 55 & 53 \\
\hline Minimum (\%DM) & 0.25 & 0.21 & 0.03 & 0.02 & 0.03 & 0.44 & 0.06 & 0.49 & 0.53 & 0.91 \\
\hline Maximum (\%DM) & 13.82 & 10.98 & 0.58 & 0.76 & 32.50 & 32.50 & 32.69 & 32.69 & 33.71 & 33.71 \\
\hline Mean (\%DM) & 1.78 & 1.59 & 0.22 & 0.17 & 11.04 & 9.25 & 11.26 & 9.53 & 12.60 & 10.54 \\
\hline SD (\%DM) & 2.59 & 2.14 & 0.14 & 0.17 & 8.71 & 7.94 & 8.75 & 7.97 & 8.29 & 7.83 \\
\hline$R^{2} p$ & 0.72 & 0.80 & 0.73 & 0.82 & 0.78 & 0.90 & 0.78 & 0.88 & 0.72 & 0.90 \\
\hline RMSEp (\%DM) & 1.38 & 1.03 & 0.07 & 0.06 & 4.31 & 2.54 & 4.34 & 2.76 & 4.38 & 2.58 \\
\hline RPDp & 1.88 & 2.08 & 1.93 & 2.24 & 2.01 & 3.13 & 2.02 & 2.88 & 1.89 & 3.03 \\
\hline Bias (\%DM)a & 0.18 & -0.16 & 0.01 & -0.01 & -1.18 & 0.27 & -1.19 & 0.17 & -0.26 & 0.37 \\
\hline
\end{tabular}

a: mean of the estimated values - means of the measured values; LV: latent variable. 
By observing separately, the parameters for the sampling performed on the discs, satisfactory calibration models were found to determine the NSC $\left(\mathrm{R}_{c \mathrm{c}}^{2}>0.67\right)$. The best model, when observed its validation with external data, was obtained for total sugars $\left(R^{2} p=0.78\right.$ and $\mathrm{RMSEp}=4.34 \%)$ and the worst for starch $\left(R^{2} p=\right.$ 0.72 and RMSEp $=1.38 \%$ ).

The material reduced to powder gave better calibration models compared to the data obtained straight from the disc $\left(R^{2} c v>0.69\right)$. In the external validation, the best models were for reducing sugars $\left(R^{2} p=0.90\right.$ and RMSEp $=2.54 \%)$ and the worst was again for starch $\left(R^{2} p=\right.$ 0.80 and RMSEp $=1.03 \%$ ). The parameters of the models found in this study are similar to those found in the literature, however in different tissues and plant species(Chen et al., 2014; Ramirez et al., 2015; Quentin et al., 2017).

According to the classification of the coefficients of determination and the RPD referred by Saeys et al. (2005), it may be inferred that for the prediction of constituents of NSC, this will quantify approximately the contents of reducing sugars and total sugars. On the other hand, for starch, sucrose and total NSC, it would only be capable of discriminating their contents between highs and lows.

More accurate models were found in the analyses made on wood reduced to powder. According to the classification used, the contents of starch and sucrose can be quantified approximately, the total sugars will be predicted optimally and the reducing sugars and total NSC will be quantified with an excellent prediction.

The collection of spectral signatures with the integrating sphere resulted in better fits when compared to the collection with the optical fiber probe. In addition to the sampling method, the physical structure of the wood must also have influenced this result. Hein et al. (2010) have stated that milled wood provides better results than solid wood on NIR prediction of chemical properties of Eucalyptus urophylla.

Figure 4 shows the relationship between the chemical reference values and the NIR-predicted values of the different structures analyzed. In general, the models yelded a satisfactory prediction power for the NSC content.

From the partial least squares regression, we constructed the graph of each non-structural carbohydrates from the perspective of the wavelength versus regression coefficients for the disc and for the wood reduced to powder (Figure 5) in order to relate the largest regression coefficients, positive and negative, with the wavenumber where a given NSC is most expressed.

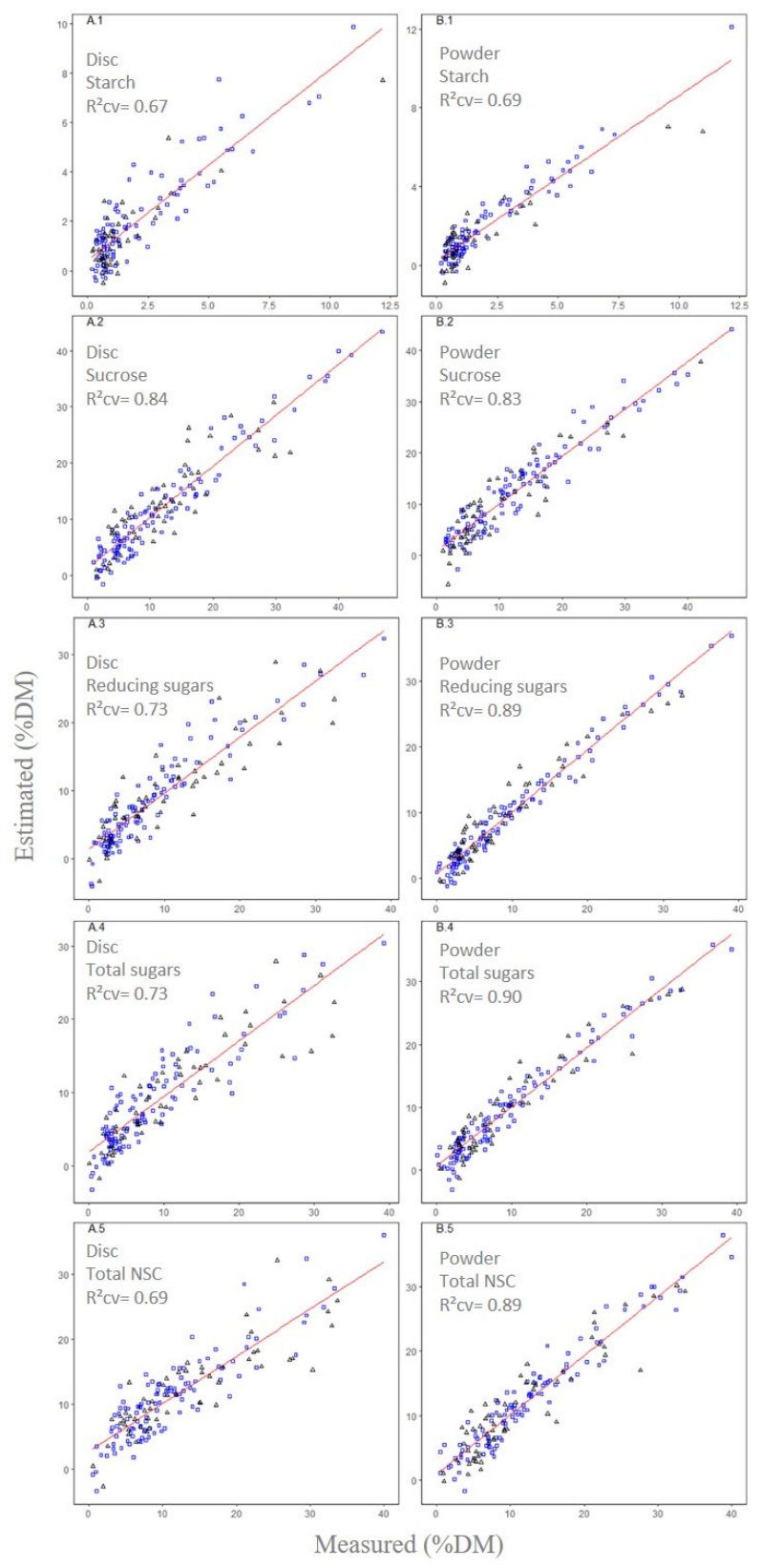

FIGURE 4 Correlation between the predicted values and the observed values for the contents of starch (I), sucrose (2) reducing sugar, (3) total sugars and (4) and total NSC (5) in Toona ciliata wood. Samples for the disc (A) and for the wood reduced to powder (B) are represented to the left and the right, respectively. Legend: $\square$ crossvalidation; $\Delta$ external validation..

The highest coefficients were found for the material reduced to powder, a fact associated with better penetration of the light beam in the spectral acquisition in the integrating sphere. The starch can be measured by the vibrational modes presented in the range of 4,200 to $4,000 \mathrm{~cm}^{-1}$ in the wood reduced to powder, where there was also a peak at $6,954 \mathrm{~cm}^{-1}$. For sucrose, the regression coefficients were not as expressive as the other NSC, 


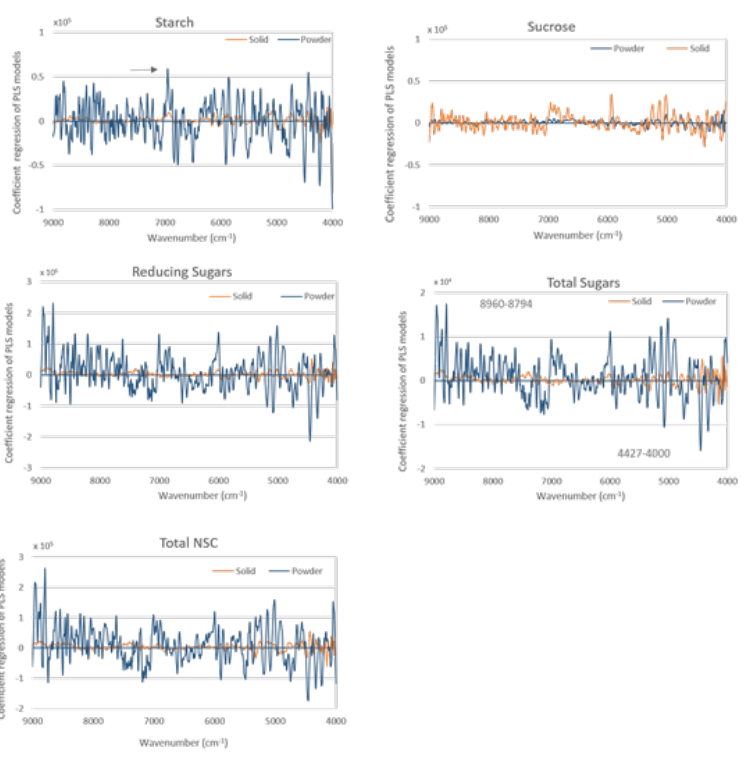

FIGURE 5 Partial least squares regression coefficients according to wavelengths for the non-structural carbohydrates in the disc and the powder of Toona ciliata wood obtained by the optical fiber and the integrating sphere.

there was also a great variation in the relationship of the coefficients with the wavelength. Reducing sugars can be detected in wavelengths in the order of 4,400-4,000 $\mathrm{cm}^{-1}$ in the material reduced to powder there were also high relationships in the bands of $8,964-8,794 \mathrm{~cm}^{-1}$. Total sugars were more present in the wavelength of 4,427 $4,076 \mathrm{~cm}^{-1}$, and in the material reduced to powder, there was also significant interference of wavelengths of 5,014 $\mathrm{cm}^{-1}$ and $8,960-8,794 \mathrm{~cm}^{-1}$. For total NSC, the spectral range with the highest relationship was $4,458-4,000$ $\mathrm{cm}^{-1}$, while in the powder there was also a relationship with the wavelengths of 8,956-8,794 $\mathrm{cm}^{-1}$. These peaks are in accordance with the information provided in Workman and Weyer (2007) and the band assignments in NIR spectra of wood reported in Schwanninger et al. (20I I). However, some peak locations differ from those found by Quentin et al. (20I7), who reported the most explanatory regression coefficients at wavelengths in the order of $5,180-5,200 \mathrm{~cm}^{-1}$ and $5,260-5,270 \mathrm{~cm}^{-1}$ for fructose and reducing sugars, respectively. According to Ramirez et al. (2015), the regions where sugars, starch and total carbohydrates were detected are located at wavelengths in the order of 5,747-5,555 $\mathrm{cm}^{-1}, 4,761$ $4,347 \mathrm{~cm}^{-1}$ and 4, 149-4,016 $\mathrm{cm}^{-1}$, respectively.

Partial least squares regression (PLS-R) analysis was also performed with $100 \%$ of the data (Table 2 ), thus obtaining a model for the quantification of NSC for other individuals.
The results show that the PLS-R calibration $\left(R^{2}>\right.$ $0.80)$, and cross-validation $\left(R^{2}>0.67\right)$ presented satisfactory statistics for the models based on the disc spectra. The models allow the quantification of non-structural carbohydrates in the approximate values, for starch, reducing sugars, totals sugars and total NSC, and good predictions for sucrose, considering $\mathrm{R}^{2}$. Based on the RPD and the classification proposed by Saeys et al. (2005), the models will allow the starch to be quantified as high or low content, sucrose will be predicted as approximate values. Reducing sugars, total sugars and total NSC can be investigated with excellent predictions and, for sucrose, the association of measured values and estimates will be excellent.

These results, as well as the works by Batten et al. (1993), Decruyenaere et al. (2012), Ramirez et al. (20I5) and Quentin et al. (20I7) demonstrated the great potential of NIR in analyzing non-structural carbohydrates in various tissue types in plants.

\section{Perspectives}

This tool becomes more useful with the increasing number of samples to be analyzed, given the decrease in the time and reagents of laboratories demanded, as well as the economy in the workforce. One strategy would be to use the predictions of the NIR by the disc or core, taken from the trees, to group or classify the genotypes with low, medium and high values of NSC. When the number of individuals is smaller, the wood can be ground, which will take a little more time and labor, but it will be possible to quantify the NSC more precisely.

With satisfactory calibrated models for both types of samples, NIR spectroscopic models can be used for studies of Toona ciliata and other genera, assisting ecologists, physiologists, and genetic plant breeders to better understand the relationship between NSC with plant growth and mortality under influence of environmental stresses.

\section{CONCLUSIONS}

The models based on the NIR spectroscopy demonstrated applicability in the quantification of the non-structural carbohydrates in the Toona ciliata wood.

All the PLSR multivariate fits for the non-structural carbohydrates were better in the wood powder samples.

The lowest $R^{2}$ of the external validation was observed for starch in the two physical forms of samples, $\mathrm{R}^{2}=0.72$ for the disc and 0.80 for the powder. The higher values were found for reducing sugars and total sugars, $R^{2}=0.78$ for the disc and 0.90 for the powder. 
TABLE 2 Descriptive statistics of the data groups.

\begin{tabular}{|c|c|c|c|c|c|c|c|c|c|c|}
\hline \multirow{2}{*}{$\frac{\text { NSC }}{\text { Sampling }}$} & \multicolumn{2}{|c|}{ Starch } & \multicolumn{2}{|c|}{ Sucrose } & \multicolumn{2}{|c|}{ Reducing sugars } & \multicolumn{2}{|c|}{ Total sugars } & \multicolumn{2}{|c|}{ Total NSC } \\
\hline & \multicolumn{2}{|c|}{ Calibration } & Disc & Powder & Disc & Powder & Disc & Powder & Disc & Powder \\
\hline Number of samples & 140 & 139 & 162 & 160 & 165 & 162 & 165 & 164 & 164 & 162 \\
\hline Number of outliers & 7 & 8 & 6 & 8 & 3 & 6 & 3 & 4 & 3 & 4 \\
\hline LV & 10 & 12 & 12 & 10 & II & 12 & II & 10 & 10 & II \\
\hline Minimum (\%DM) & 0.19 & 0.19 & 0.02 & 0.02 & 0.03 & 0.03 & 0.06 & 0.06 & 0.49 & 0.49 \\
\hline Maximum (\%DM) & 12.17 & 12.17 & 0.85 & 0.85 & 39.01 & 39.07 & 39.34 & 30.34 & 40.01 & 40.01 \\
\hline Mean (\%DM) & 1.91 & 1.91 & 0.21 & 0.21 & 9.20 & 9.34 & 9.42 & 9.73 & 11.45 & 14.28 \\
\hline SD (\%DM) & 2.12 & 2.10 & 0.17 & 0.17 & 8.01 & 8.21 & 8.05 & 8.41 & 7.77 & 9.21 \\
\hline $\mathrm{R}^{2} \mathrm{C}$ & 0.80 & 0.90 & 0.91 & 0.91 & 0.85 & 0.95 & 0.85 & 0.93 & 0.83 & 0.95 \\
\hline RMSEc (\%DM) & 0.94 & 0.66 & 0.05 & 0.05 & 3.04 & 1.76 & 3.06 & 2.18 & 3.19 & 1.92 \\
\hline Validation $\mathrm{m}$ & & Cros & tion & & & & & & & \\
\hline $\mathrm{R}^{2} \mathrm{CV}$ & 0.67 & 0.74 & 0.83 & 0.84 & 0.77 & 0.91 & 0.77 & 0.89 & 0.74 & 0.90 \\
\hline RMSEcv (\%DM) & 1.21 & 1.08 & 0.07 & 0.07 & 3.87 & 2.53 & 3.89 & 2.76 & 3.97 & 2.65 \\
\hline RPDCV & 1.74 & 1.76 & 2.44 & 2.50 & 2.07 & 3.25 & 2.07 & 3.04 & 1.96 & 3.47 \\
\hline
\end{tabular}

The values of RPD followed the trend of $R^{2}$ and were lower for starch, I.88 for the disc and 2.08 for the powder. The largest were for the reducing sugars, 2.01 for the disc and 3.13 for the powder.

The root mean square error (\% DM) was lower for sucrose, $0.07 \%$ for the disc and $0.06 \%$ for the powder. While the largest errors were verified for the total non-structural carbohydrates, in the order of $4.38 \%$ for the disc and $2.58 \%$ for the powder.

Depending on the sample size, the use of the wood disc for collecting the spectra via optical fiber can be used for the qualitative determination of the samples. For the most precise quantification, wood must be reduced to powder, and the integrating sphere must be used for collecting the spectra.

\section{ACKNOWLEDGEMENTS}

The authors thank the Universidade Federal de Lavras (Brazil), especially to the Wood Science and Technology Laboratory and Biology Department for supporting the experimental work and to Bela Vista Florestal for providing trees. This study was financed in part by the Coordenação de Aperfeiçoamento de Pessoal de Nível Superior - Brasil (CAPES) - Finance Code 00I, Foundation for Research Support of the State of Minas Gerais (FAPEMIG) and National Council for Scientific and Technological Development (CNPq, process no. 405085/2016-8). P.R.G. Hein were supported by CNPq (process no. 303675/2017-9) grants.

\section{REFERENCES}

BATTEN, G. D.; BLAKENEY, A. B.; MCGRATH, V.B.; CIAVERELLA, S. Non-structural carbohydrate: Analysis by near infrared reflectance spectroscopy and its importance as an indicator of plant growth. Plant and Soil, v. I55, n. I, p. 243-246, 1993.

BRUKER, Opus 5.5, Bruker Optik, Ettlingen, Germany. 2005.
CHEN, S. F; DANAO, M. G. C.; SINGH, V.; \& BROWN, P. J. Determining sucrose and glucose levels in dual-purpose sorghum stalks by Fourier transform near infrared (FTNIR) spectroscopy. Journal of the Science of Food and Agriculture, v. 94, n. 12, p. 2569-2576, 2014.

DECRUYENAERE, V.; CLÉMENT, C.; AGNEESSENS, R.; LOSSEAU, C.; STILMANT, D. Development of nearinfrared spectroscopy calibrations to quantify starch and soluble sugar in the roots of Rumex obtusifolius. Weed research, v. 52, n. I, p. I-5, 2012.

DESLAURIERS, A.; GIOVANELLI, A.; ROSSI, S.; CASTRO, G.; FRAGNELLI, G.; TRAVERSI, L. Intra-annual cambial activity and carbon availability in stem of poplar. Tree Physiology, v. 29, n. 10, p. 1223-1235, 2009.

ESTOPA, R.A.; MILAGRES, F.R.; OLIVEIRA, R.A,; HEIN, P.R.G. NIR spectroscopic models for phenotyping wood traits in breeding programs of Eucalyptus benthamii. Cerne, v. 23, n. 3, p. 367-375, 2017.

HEIN, P. R. G.; LIMA, J. T.; CHAIX, G. Effects of sample preparation on NIR spectroscopic estimation of chemical properties of Eucalyptus urophylla S.T. Blake wood. Holzforschung. v.6, n. I, p.45-54, 2010.

HOCH, G.; RITCHER, A.; KORNER, C. Nonstructural carbon compounds in temperature forest trees. Plant, Cell \& Enviornment, v. 26, n. 7, p. I067-108I, 2003.

KENNARD, R. W.; STONE, L. A. Technometrics. Comp Aided Design Exp, v. I I, p. I37-I48, 1969.

KÖPPEN, W. Climatologia. México. Fundo de Cultura Econômica, 1948.

LOCOSSELLI, G.; BUCKERIDGE, M.S. Dendrobiochemistry, a missing link to further understand carbon allocation during growth and decline of trees. Trees, v. 31, n. 6, p. I7451758, 2017.

MCDOWELL, N. G.; BEERLING, D. J.; BRESHEARS, D. D.; FISHER, R. A.; RAFFA, K. F.; STITT, M. The interdependence of mechanisms underlying climate-driven vegetation mortality. Trends in Ecology \& Evolution, v. 26, n. 10, p. 523-532, 2011. 
MILLER, G. L. Use of dinitrosalicylic acid reagent for determination of reducing sugar. Analytical Chemistry, v. 31, n. 3, p. 426-428, 1959.

NARDINI, A.; GULLO, M. A. Lo; SALLEO, S. Refilling embolized xylem conduits: is it a matter of phloem unloading? Plant Science, v. I80, n. 4, p. 604-6II, 201 I.

NUNES, C. A; FREITAS, M. P.; PINHEIRO, A. C. M.; BASTOS, S. C. Chemoface: a novel free user-friendly interface for chemometrics. Journal of the Brazilian Chemical Society, v. 23, n. I I, p. 2003-20I0, 2012.

O'BRIEN, M. J.; LEUZINGER, S.; PHILIPSON, C. D.; TAY, J.; HECTOR, A. Drought survival of tropical tree seedlings enhanced by non-structural carbohydrate levels. Nature Climate Change, v. 4, n. 8, p. 710, 2014.

PASQUINI, C. Near infrared spectroscopy - A mature analytical technique with new perspectives - A review. Analytica Chimica Acta, v. 1026, p. 8-36, 2018.

POPP, M.; LIED, W.; MEYER, A. J.; RITCHER, A.; SCHILLER, P.; SCHWITTE, H. Sample preservation for determination of organic compounds: microwave versus freeze-drying. Journal of Experimental Botany, v. 47, n. 10, p. 1469-1473, 1996.

QUENTIN, A. G.; BEADLE, C. L.; O'GRADY, A. P.; PINKARD, E. A. Effects of partial defoliation on closed canopy Eucalyptus globulus Labilladière: growth, biomass allocation and carbohydrates. Forest Ecology and Management, v. $26 \mathrm{I}$, n. 3, p. 695-702, $201 \mathrm{I}$.

QUENTIN, A. G.; RODEMANN, T.; DOUTRELEAU, M. F; MOREAU, M.; DAVIES, N.W.; MILLARD, P. Application of near-infrared spectroscopy for estimation of nonstructural carbohydrates in foliar samples of Eucalyptus globulus Labilladière. Tree Physiology, v. 37, n. I, p. I 3 I 141, 2017.

RAMIREZ, J. A.; POSADA, J. M.; HANDA, I. T.; HOCH, G.; VOHLAND, M.; MESSIER, C.; REU, B. Near-infrared spectroscopy (NIRS) predicts non-structural carbohydrate concentrations in different tissue types of a broad range of tree species. Methods in Ecology and Evolution, v. 6, n. 9, p. 1018-1025, 2015.
SAEYS, W.; MOUAZEN, A. M.; RAMON, H. Potential for onsite and online analysis of pig manure using visible and near infrared reflectance spectroscopy. Biosystems Engineering, v. 9I, n. 4, p. 393-402, 2005.

SAVITZKY, A.; GOLAY, M.J.E. Smoothing and differentiation of data by simplified least-squares procedures. Analytical Chemistry, v. 36, n. 8, p.1627-1639, 1964.

SCHIMLECK, L. R. Near infrared spectroscopy: a rapid, nondestructive method for measuring wood properties and its application to tree breeding. New Zealand Journal of Forestry Science, v. 38, n. I, p. 14-35, 2008.

SCHWANNINGER, M.; RODRIGUES, J.C.; FACKLER, K. A review of band assignments in near infrared spectra of wood and wood components. Journal of Near Infrared Spectroscopy, v. 19, p. 287-308, 2011.

TSUCHIKAWA, S. KOBORI, H. A review of recent application of near infrared spectroscopy to wood science and technology. Journal of Wood Science, v. 6I, n. 3, p. $213,2015$.

VAN HANDEL, E. V. Direct microdetermination of sucrose. Anal Biochem. 22, p. 280-283, 1968.

VIANA, L.C.; TRUGILHO, P.F; HEIN, P.R.G.; LIMA, J.T. SILVA, J.R.M. Predicting morphological characteristics and basic density of Eucalyptus wood using the NIRS technique. Cerne, v. I5, n.4, 42I-429, 2009

WANG, Y.; MAO, Z.; BAKKER, M. R.; KIM, J. H.; BRANCHERIAU, L.; LECLERC, R.; SELLI, L.; REY, H.; JOURDAN, C.; STOKES, A. Linking conifer root growth and production to soil temperature and carbon supply in temperate forests. Plant and Soil, v. 426, n. I-2, p. 33-50, 2018.

WORKMAN, J.J.; WEYER L. Practical Guide to Interpretive Near-Infrared Spectroscopy. CRC Press, Boca Raton, Florida, 2007, p. 332.

YEMM, E. W.; WILLIS, A. J. The estimation of carbohydrates in plant extracts by anthrone. Biochemical Journal, v. 64, p. $81-96,1954$.

ZANANDREA, I.; ALVES, J. D.; DEUNER, S.; DE GOULART, F. P.; HENRIQUE, P. D. C.; SILVEIRA, N. M. Tolerance of Sesbania virgata plants to flooding. Australian Journal of Botany, v. 57, n.8, p. 66I-669, 2010. 